\title{
Effect of NGF on the Survival of Rat Retinal Ganglion Cells Following Optic Nerve Section
}

\author{
G. Carmignoto, ${ }^{1}$ L. Maffei, ${ }^{2}$ P. Candeo, ${ }^{1}$ R. Canella, ${ }^{1}$ and C. Comelli ${ }^{1}$ \\ 'Fidia Research Laboratories, Department of Eye Research, Abano Terme 35031, Italy, and 'Istituto di Neurofisiologia del \\ C.N.R.
}

The ability of NGF (2.5S subunit) to support the survival of adult rat retinal ganglion cells (RGCs) and optic nerve fibers after intracranial section of the optic nerve was investigated. NGF was injected intraocularly at a dose of $3 \mu \mathrm{g} /$ injection every $2.3 \mathrm{~d}$ from the day of axotomy to analysis. Control animals received cytochrome $c$ injections. The survival of RGCs was analyzed in whole-mounted retinas after either cresyl violet staining or labeling with HRP applied to the proximal stump of the optic nerve. Survival times were 5 and 7 weeks. Diameter distribution and number of myelinated optic nerve fibers were assessed in ultrathin cross sections of the optic nerve.

We found that RGCs surviving axotomy were much more numerous following NGF treatment compared with controls. Large-size cells were, in particular, preserved by NGF treatment. The quantitative ultrastructural studies indicated that the number of myelinated optic nerve fibers at 5 and 7 weeks postaxotomy was significantly greater in the NGF group with respect to the cytochrome $c$ group. In agreement with the results obtained at the level of the RGCs, large-diameter axons were, in particular, preserved. We conclude that NGF injected intraocularly is effective in promoting the survival of RGCs and optic nerve fibers at least for a period as long as 7 weeks after intracranial section of the optic nerve.

Retinal ganglion cells (RGCs) of lower vertebrates respond to the optic nerve section by regenerating the injured axons and reestablishing functional connections (for review, see Grafstein, 1986). RGCs of mammals do not possess similar regenerative capacities (Maffei and Fiorentini, 1981; Perry, 1981; Grafstein and Ingoglia, 1982; Hollander et al., 1984; Misantone et al., 1984), although signs of axonal regrowth have been observed in selected experimental conditions (McConnel and Berry, 1982; Richardson et al., 1982; Barron et al., 1986). The reasons for this limited regeneration potential are poorly understood. Evidence is now emerging that the survival and regeneration of injured neurons in the CNS depend, at least in part, on their interactions with surrounding neuronal and non-neuronal tissues (for review, see Aguayo, 1985). Trophic factors have been demonstrated to play important roles for neuronal survival and general growth capabilities in development (Landmesser and

\footnotetext{
Received Feb. 26, 1988; revised Aug. 1, 1988; accepted Aug. 29, 1988.

We wish to thank Drs. A. Fiorentini, A. Leon, and S. D. Skaper for carefully correcting the manuscript.

Correspondence should be addressed to Dr. Giorgio Carmignoto, Fidia Research Laboratories, Via Ponte della Fabbrica 3/A, 35031 Abano Terme (PD), Italy.

Copyright $(C) 1989$ Society for Neuroscience $0270-6474 / 89 / 041263-10 \$ 02.00 / 0$
}

Pilar, 1974; Varon and Adler, 1980), as well as in the adult state (for review, see Varon et al., 1987). The prototype of such neuronotrophic factors, the nerve growth factor (NGF) (Levi-Montalcini and Angeletti, 1968; Greene and Shooter, 1980), has now been found to be active at the level of the CNS, especially on forebrain cholinergic neurons (Hefti et al., 1984; Hefti, 1986; Williams et al., 1986; Kromer, 1987; for review, see Thoenen et al., 1987).

In the present study we investigated the effect of repetitive intraocular injections of NGF on the survival of RGCs after intracranial section of the optic nerve. NGF is shown here to promote the survival of a large number of $\mathrm{RGC}$ for period as long as 7 weeks after axotomy. Similar effects were observed at the level of the optic nerve fibers.

\section{Materials and Methods}

Animals. Experiments were performed on adult male Long Evans hooded rats. Animals were housed 2 per cage, in a temperature- and humidity-controlled room $\left(22^{\circ} \mathrm{C}, 50 \%\right.$, respectively) on a 12 hour lightdark cycle and were allowed food and water ad libitum.

Optic nerve section. In order to avoid possible damage to the blood supply of the retina, the optic nerve was transected intracranially. Animals were deeply anesthetized with $2.5 \mathrm{ml} / \mathrm{kg}$ of a mixture of $2.1 \mathrm{gm}$ chloral hydrate and $0.5 \mathrm{gm}$ sodium pentobarbital in $50 \mathrm{ml}$ solution. A frontal craniotomy was made and a portion of frontal cortex was then aspirated to allow a clear visualization of the right optic nerve. Transection was performed between the optic foramen and the chiasm. The completeness of the transection in each experimental animal was subsequently verified at the light microscopic level in semithin cross sections $(0.5-1.0 \mu \mathrm{m})$ stained with toluidine blue. Operated animals were divided into NGF and cytochrome c-treated groups. Postoperative survival was 5 and 7 weeks.

Drugs and treatment. The $2.5 \mathrm{~S}$ subunit of NGF was purified from adult male mouse submandibular glands according to the method of Bocchini and Angeletti (1969) and dissolved in buffered saline. The biological activity of the purified NGF, evaluated utilizing fetal chicken dissociated dorsal root ganglion neurons in vitro (Skaper and Varon, 1982 ), was in the range of $1-2 \mathrm{ng}$ protein/trophic unit. Sterile NGF was injected intraocularly every $2.3 \mathrm{~d}$ from the day of optic nerve section to the day of death at a dose of $3 \mu \mathrm{g} /$ injection in approximately $3 \mu \mathrm{l}$ solution. Rats were anesthetized with diethyl cthcr. Control animals received equal amounts of cytochrome c (a protein with similar molecular weight and isoelectric point to NGF). Injections were made by means of a glass pipette, with a $50 \mu \mathrm{m}$ tip, connected via a polyethylene tube with a $25 \mu$ l Hamilton syringe. The tip of the pipette was inserted under microscopic guidance through the dorsal limbus of the eye.

Nissl stain. Animals were given a lethal dose of Nembutal and perfused intracardially with normal saline, followed by $10 \%$ formolsaline. Retinas were dissected, whole-mounted, stained with cresyl violet as described by Perry and Cowey (1979), dehydrated, and coverslipped. In total, 16 animals were examined. Nine animals (6 NGF-treated and 3 cytochrome c-treated) were analyzed 5 weeks after optic nerve section. Two animals per group were analyzed at 7 weeks. The retinas of 3 adult animals with intact optic nerves were also examined. 
$H R P$. The retrograde transport of HRP was used to examine the survival of RGCs after optic nerve section. Rats were anesthetized with chloral hydrate. The orbita was opened by a dorsal approach, the superior rectus muscle was removed and the right optic nerve was prepared free, taking care not to damage the retinal blood supply. Small pieces of Spongestan, previously saturated with a $25 \%$ solution of HRP, were inserted into the proximal stump of the optic nerve $3 \mathrm{~mm}$ from the globe. Twenty-four hours later the animals were sacrificed with an intraperitoneal injection of chloral hydrate and immediately perfused with normal saline followed by $1.5 \%$ paraformaldehyde in $0.1 \mathrm{M}$ phosphate buffer, $\mathrm{pH}$ 7.4. Retinas were dissected and whole-mounted. The preparations were postfixed in $2 \%$ glutaraldehyde for $1 \mathrm{hr}$, transferred to phosphate buffer, and reacted for HRP histochemistry according to the method of Hanker et al. (1977), as modified by Perry and Linden (1982). After dehydration retinas were cleared in xylene and coverslipped. In all, 19 animals were examined by this procedure. Four animals per group were examined 5 weeks after optic nerve section. Nine animals (4 NGF-treated and 5 cytochrome c-treated) were analyzed at 7 weeks. The retinas of 2 adult animals with intact optic nerves were also analyzed. One of these received repetitive injections of NGF every $2.3 \mathrm{~d}$, at a dose of $3 \mu \mathrm{g} /$ injection for 5 weeks.

Analysis. Soma size of HRP-labeled cells were taken from camera lucida drawings at $560 \times$ magnification. The equivalent circle diameter of cell profiles was calculated from the drawings with an Ibas-1 imageanalyzing system. All the HRP-labeled cells within the field restricted by an eyepiece graticule $\left(0.059 \mathrm{~mm}^{2}\right)$ were drawn. More than 200 cells were measured in each retina. Counts of the absolute number of cells above $15 \mu \mathrm{m}$ in diameter were made by drawing all the apparently large HRP-labeled cells in each retina at $560 \times$ magnification and then measuring cell diameter by means of the Ibas-1 computer. Counts of cell densities in Nissl- and HRP-stained retinas were made with the use of the graticule $\left(0.00958 \mathrm{~mm}^{2}\right)$ at $1420 \times$ magnification. Sample fields were taken at $0.25 \mathrm{~mm}$ intervals across the nasal and temporal retina from the optic disk to the periphery. In Nissl preparations, only cells with a soma diameter larger than $8 \mu \mathrm{m}$ were considered.

For statistical analysis, data from cytochrome c- and NGF-treated animals were compared using Student's $t$ test.

${ }^{22 s} I-N G F$ retrograde transport. Iodinated NGF (specific activity, 76 $\mu \mathrm{Ci} / \mu \mathrm{g}$ ) was injected into the right superior colliculus (SC) after aspiration of the overlying cortex, using a micropipette attached to a Hamilton syringe. The tip of the pipette was lowered into the $\mathrm{SC}$ using a micromanipulator under microscopic guidance. The tip was inserted into the SC approximately $0.5 \mathrm{~mm}$ below the surface. A total of 0.5 $\mu \mathrm{Ci} /{ }^{125}$ I-NGF in $10 \mu \mathrm{l}$ solution was slowly infused. Three animals were perfused with normal saline 4,8 , and $16 \mathrm{hr}$ after a single injection of ${ }^{125}$ I-NGF. The retinas contralateral and ipsilateral to the injected SC, optic nerves, and superior and inferior colliculi were then dissected. Each tissue sample was digested with $10 \%$ SDS (wt/vol). Total radioactivity was determined after addition of Dimilume (Packard) using a Packard Tricarb (model 4600) gamma counter.

Electron microscopy. Animals were deeply anesthetized with chloral hydrate and intracardially perfused with heparinized saline followed by a mixture of $1.5 \%$ paraformaldehyde and $2 \%$ glutaraldehyde in $0.1 \mathrm{M}$ phosphate buffer, $\mathrm{pH}$ 7.4. Both optic nerves were dissected out. The lesioned optic nerve was divided into proximal and distal stumps. Blocks were then immersed in cold fixative for an additional $2 \mathrm{hr}$, rinsed in $0.1 \mathrm{M}$ phosphate buffer, and postfixed in a fresh solution of $1.5 \%$ osmium tetraoxide, dehydrated in alcohols and propylene oxide, and finally embedded in Araldite. Ultrathin cross sections were collected from the proximal stump immediately after a semithin cross section taken $2 \mathrm{~mm}$ from the back of the globe. The level of the section was determined by means of a micrometer slide under microscopic control. Ultrathin sections were then collected on thin-line 400 mesh grids and stained with $2 \%$ uranyl acetate and a lead citrate solution. Each nerve was photographed in a noninterrupted session using a Philips 400 EMT. A photomicrograph was taken systematically at $3600 \times$ magnification for each grid window across the entire section of the nerve. Photomicrographs were also printed at $360 \times$ image magnification for calculation of the nerve section area. This low-power montage was also used to divide the nerve into 3 distinct regions: a peripheral belt expanding from perineurium toward the center of the nerve, $40 \mu \mathrm{m}$ wide; a paracentral belt from the peripheral belt border toward the center, $90 \mu \mathrm{m}$ wide; and a third central region, that is, the degenerating "core" of the nerve. Sampled micrographs were taken with strict reference to the limits of the 3 regions and to the absence of large blood vessels. The pool of micrographs was proportional in each region to its contribution to the total section area of the nerve. The caliber distribution of at least 200 myelinated fibers per nerve was measured. The equivalent circle diameter of an axonal profile was calculated from the prints with an Ibas-1 imageanalyzing system at a final magnification of $7200 \times$. All measurements excluded the myelin sheath. No correction for shrinkage was applied. Counts of myelinated fibers were made on the prints $(7200 \times)$ using the protocol of Gundersen (1977), which compensates for the micrograph edge effect. The total number of myelinated axons was estimated by multiplying the number of counted axons in each of the 3 regions by the ratio of the region area and the sample area. Sampled area corresponds to a minimum of $10 \%$ of total thin nerve section area.

In all, 11 animals were examined. Four of these had both optic nerves transected in the same surgical session. In these animals, NGF was injected into the right eye and cytochrome $c$ into the left eye. Two animals were examined at 5 weeks and 2 at 7 weeks postaxotomy. Seven more animals had only the right optic nerve transected. Four of these were treated with cytochrome $c$, and were examined 1 at 5 weeks and 3 at 7 weeks. The remaining 3 animals were treated with NGF and were analyzed at 7 weeks.

\section{Results}

The optic nerves of adult rats were intracranially transected, either unilaterally or bilaterally. The effects of prolonged repetitive intraocular injections of NGF were studied 5 and 7 weeks after axotomy and compared with controls that had received cytochrome c.

In order to assess the effect of NGF on the survival of RGCs, several methods were used: (1) evaluation of RGCs on Nisslstained, whole-mounted retinas; (2) evaluation of RGCs following application of HRP to the proximal stump of the optic nerve; and (3) evaluation of the number and size of myelinated fibers in the proximal stump of the optic nerve at the light and electron microscopic levels.

\section{Evaluation of surviving $R G C s$ in Nissl preparations}

A representative area of the ganglion cell layer of a normal retina is shown in Figure $1 \mathrm{~A}$. Neurons are densely packed, and several large ganglion cells are distinguishable. A control retina of a rat treated with cytochrome $\mathrm{c}$ for 5 weeks after optic nerve section is shown in Figure $1 B$. Note that the density of neurons is significantly reduced, and large cells are practically absent. Figure $1 C$ shows the retina of a rat treated with NGF for 5 weeks after optic nerve section. Note that in this retina the density of neurons is greater than that observed in cytochrome $c$-treated animals, and several large cells are present. These observations were confirmed in all NGF-treated retinas $(n=8)$. Quantitative evaluation of the densities of neurons in the ganglion cell layer expressed as the number of cells $/ \mathrm{mm}^{2}$, at 5 weeks postaxotomy, gave a mean of $697 \pm 61$ for NGF-treated retinas $(n=6)$ and $383 \pm 37$ for cytochrome c-treated retinas $(n=3)(p<0.05)$; at 7 weeks postaxotomy the mean density of neurons was 573 $\pm 86(n=2)$ in NGF retinas, and $252 \pm 34(n=2)$ in cytochrome $c$ retinas. In normal retinas, the mean number of cells $/ \mathrm{mm}^{2}$ was calculated to be $1899 \pm 131(n=3)$. In all retinas, only cells with a soma diameter larger than $8 \mu \mathrm{m}$ were counted.

However, it has to be taken into account that Nissl staining does not allow unequivocal identification of all RGCs that survive optic nerve section. This difficulty is particularly true for small ganglion cells, which are almost indistinguishable from amacrine cells and glia. In order to avoid this difficulty, we repeated the same experiment by using a different technique that allows for the unequivocal identification of surviving RGCs. In these preparations we labeled these RGCs by the retrograde transport of HRP applied to the proximal stump of the optic nerve. 

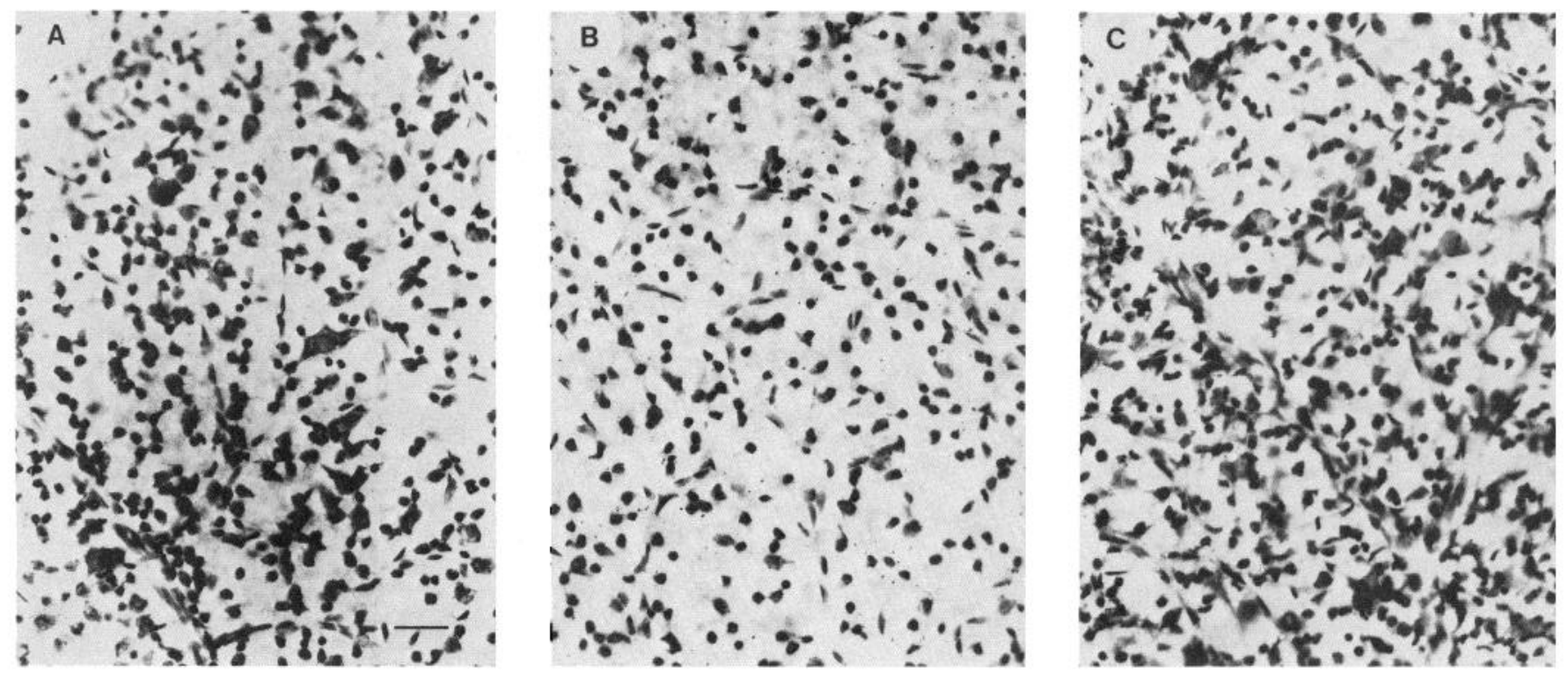

Figure 1. Photomicrographs of representative regions of the ganglion cell layer in whole-mounted retinas stained with cresyl violet. $A$, Normal adult rat retina; $B$, cytochrome c retina 5 weeks after optic nerve section; $C$, NGF retina 5 weeks after optic nerve section. Note the presence of large cells and the higher density of neurons in the NGF with respect to the cytochrome c retina. Scale bar, $20 \mu \mathrm{m}$ for all micrographs.

\section{Evaluation of surviving RGCs in HRP preparations}

A remarkable number of RGC axons both in control and experimental retinas retain their capacity to transport HRP retrogradely to the cell bodies for a relatively long time after optic nerve section. Seventeen animals with the right optic nerve intracranially transected were examined. Eight animals were treated with NGF and 9 with cytochrome c.

Examples of corresponding central and peripheral regions of 2 retinas that received repetitive injections for 7 weeks of either NGF $(A, C)$ or cytochrome c $(B, D)$ after optic nerve section, are shown in Figure 2. As already observed in Nissl-stained retinas, many large RGCs were present in the NGF-treated retinas, whereas there are very few in the cytochrome c-treated retinas. In addition, the dendritic trees of ganglion cells in all the NGF retinas appear rather healthy, while in the cytochrome $\mathrm{c}$ retinas they are markedly shrunken.

A quantitative evaluation of the number of HRP-labeled RGCs surviving optic nerve sections proved to be difficult. Indeed, application of HRP to the proximal stump of the degenerating optic nerve resulted in many cases in a nonuniform labeling of the RGCs in the different retinal sectors. This technical problem refers particularly to small RGCs, while large RGCs are more evenly distributed in the whole retina, probably because HRP is better transported by large-caliber axons. Thus, in these HRP preparations we counted only RGCs soma diameters greater than $15 \mu \mathrm{m}$. We postponed quantitative evaluation of the degree of RGC survival to a more reliable approach, namely, the count of myelinated optic nerve fibers at the electron microscopic level. The results are shown in Figure 3, $A, B$, in which dots indicate the positions of RGCs with soma diameters greater than $15 \mu \mathrm{m}$. Five weeks after optic nerve section, the number of cells in each retina varied appreciably from retina to retina. However, on computing the mean number of cells for all retinas, we obtained a value of $204 \pm 88$ for the NGF group compared with $52 \pm 22$ in the cytochrome c group. Seven weeks after optic nerve section the differences were more striking: large cells were rare in cytochrome $\mathrm{c}$ retinas $(25 \pm 11)$ but were still numerous in NGF retinas $(186 \pm 68 ; p<0.001)$. Indeed, the number of large cells in NGF retinas is not significantly decreased from 5 to 7 weeks after optic nerve section (204 vs 186). It should be pointed out that the great majority of cells with diameters greater than $15 \mu \mathrm{m}$ can be classified as type 1 ganglion cells, on the basis of their dendritic trees (Perry, 1979). In cytochrome $\mathrm{c}$ retinas, especially 7 weeks after optic nerve section, marked shrinkage of the dendritic trees makes cell identification rather uncertain.

In the preparations in which HRP-labeled cells resulted, uniformly distributed with different retinal sectors, the density (cells/ $\mathrm{mm}^{2}$ ) of HRP-labeled cells was also determined. Seven weeks after optic nerve section the mean density of neurons in $2 \mathrm{NGF}$ retinas (R14 and R18) was $366 \pm 16$, while in 2 cytochrome c retinas (R13 and R19) was $199 \pm 33$.

\section{Soma size distribution of surviving cells}

The soma size distribution of RGCs retrogradely labeled with HRP in a retina of a rat with intact optic nerves that received repetitive intraocular injections of NGF for 5 weeks was compared with that of a normal control retina of an untreated rat (Table 1). The cell size distributions in the 2 groups are similar.

The cell size distribution of RGCs in both cytochrome $\mathrm{c}$ and NGF retinas was obtained from uniformly HRP-impregnated retinas and from well-impregnated sectors of retinas that were not uniformly HRP-labeled. The summary histogram of the cell size distribution in the cytochrome c retinas, 5 weeks after optic nerve transection, is reported in Figure $4 A$. Compared with a normal retina, there is a marked decrease in the number of largesize cells and a relative increase in the number of small ones. Note the presence of a class of small cells between 4 and $6 \mu \mathrm{m}$ in diameter that is absent in the normal retina. The degree of general atrophy can be more readily appreciated by considering 

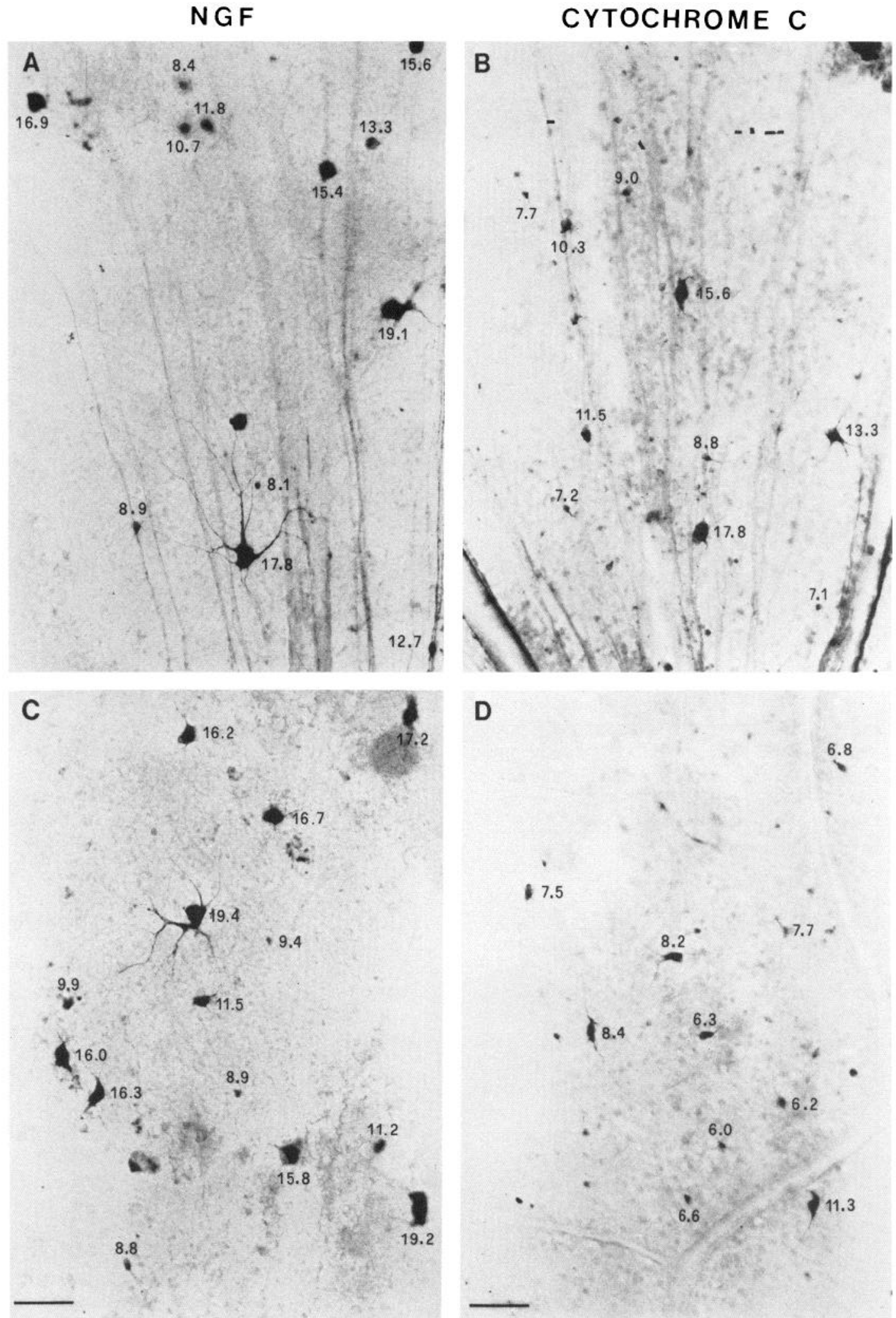

Figure 2. Surviving RGCs retrogradely labeled with HRP, 7 weeks after optic nerve section. Central $(A)$ and peripheral $(C)$ regions of a retina of a rat treated with NGF; corresponding central $(B)$ and peripheral $(D)$ regions of a retina of a rat treated with cytochrome c. The number beside each cell indicates its diameter. Many large RGCs are present in the NGF retina, whereas they are rare in the cytochrome c retina. Scale bar, 25 $\mu \mathrm{m}$ in all micrographs. 
A

CYTOCHRONE C

- R1 -

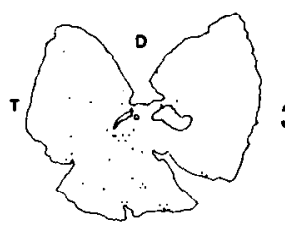

34

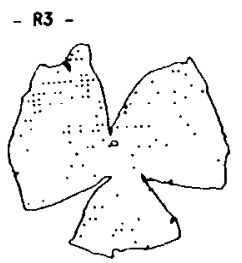

110

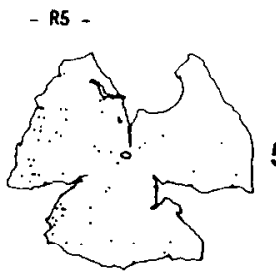

57

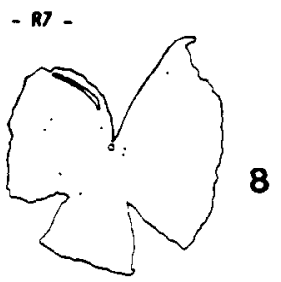

5 WEEKS
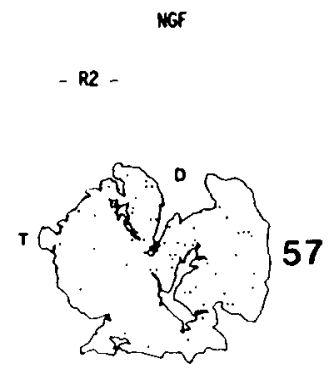

$-R^{4}-$

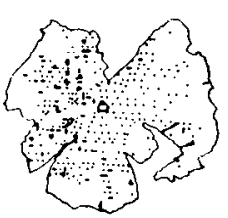

381

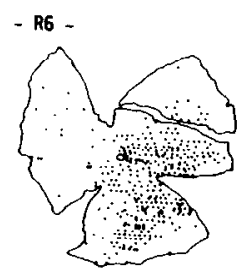

331

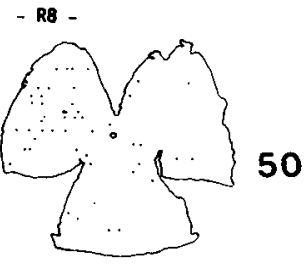

B

CrTOCHRONE C

7 WEEKS

R11 -

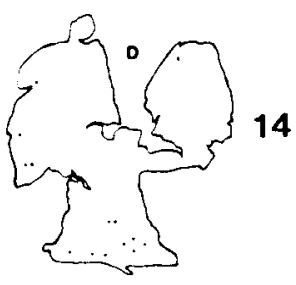

14

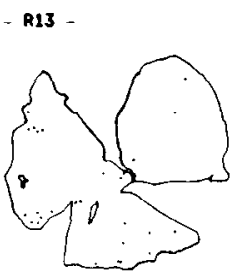

28
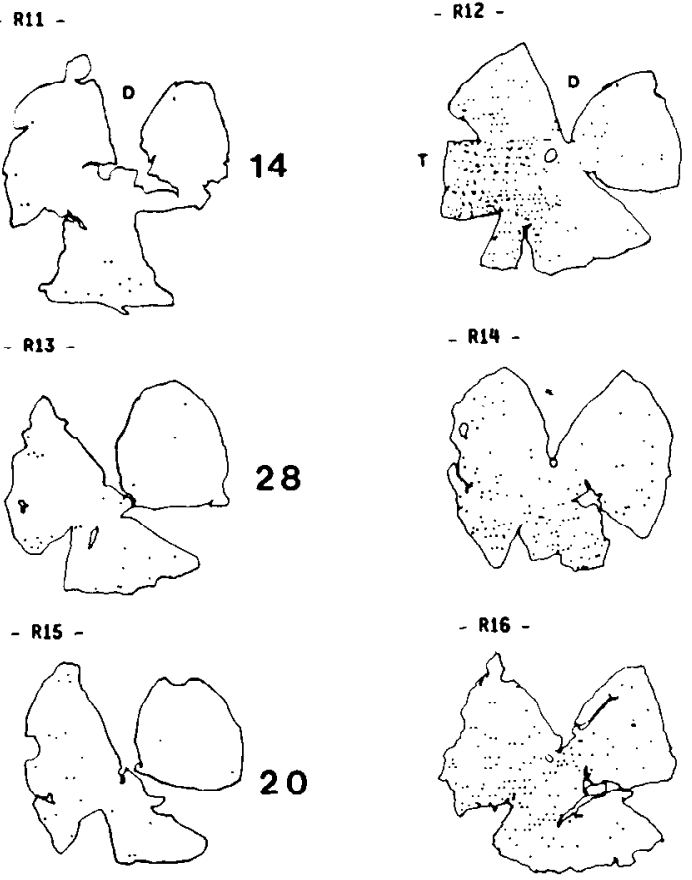

270

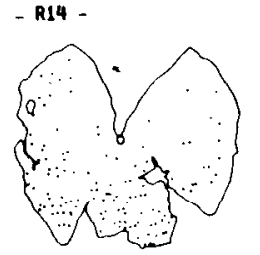

127
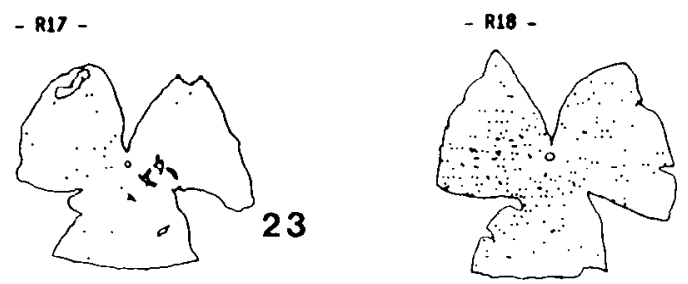

213

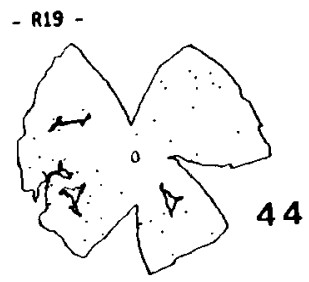

Figure 3. Outline drawings of cytochrome $\mathrm{c}$ and NGF retinas $5(A)$ and $7(B)$ weeks after optic nerve section. Each dot indicates the position of each retinal ganglion cell retrogradely labeled with HRP, with a soma diameter above $15 \mu \mathrm{m}$. The absolute number of large cells per retina is indicated to the right of cach drawing. $D$, dorsal; $T$, temporal.

the mean value of the medians which is strongly reduced with respect to normal ( 8.2 vs 11.5 ). The size distribution of cells 7 weeks after axotomy is similar to that obtained at 5 weeks, thereby suggesting that the soma of surviving cells does not further shrink between 5 to 7 weeks (Fig. 4, $A, B$ ).

In the retinas treated with NGF, a modest increase in the number of small cells was observed (Fig. 4A) 5 weeks postaxotomy. Generally, the distribution pattern of cell size was similar to, and in some cases indistinguishable from, that of the normal retina. The mean median value $(11.8 \pm 0.84)$ was significantly different from that of the cytochrome $c$ group $(8.2 \pm 0.34 ; p<$ 0.01 ; Table 1). At 7 weeks, a highcr proportion of small cells was observed in the NGF retinas, suggesting a certain degree of soma atrophy (mean median value, $10.4 \pm 0.64$ ). Large cells showed an approximately normal soma size distribution. Thus, it appears that some cells do present a shrinkage of their soma, while others do not. The mean median value is also significantly different from that of the cytochrome $c$ group $(8.5 \pm 0.47 ; p<$ 0.05 ; Table 1).

\section{Optic nerve fibers: ultrastructural observations}

As previously pointed out, the application of HRP to the degenerating stump of the optic nerve can result in a nonuniform labeling of the RGCs in the different sectors of the retina. In order to evaluate the NGF effect quantitatively, we determined the number and diameter distribution of myelinated optic nerve fibers at the electron microscopic level. The analysis was performed on thin cross sections of the intraorbital segment of the optic nerve, $2 \mathrm{~mm}$ from the back of the globe. In order to allow for direct comparison between NGF and cytochrome c groups, 4 animals had both optic nerves transected in the same surgical session. The right eye was injected with cytochrome $\mathrm{c}$ and the 
5 WEEKS

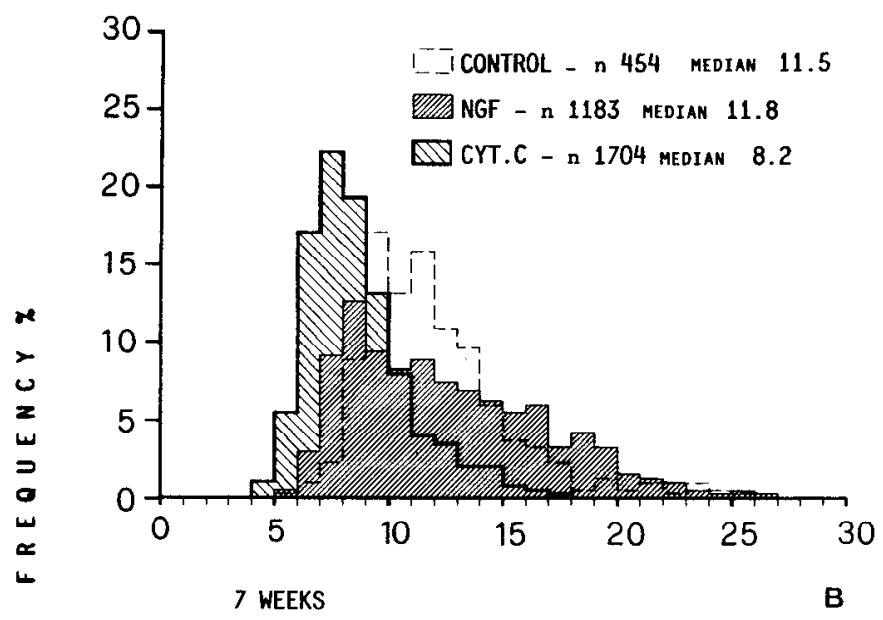

Figure 4. Soma size summary histograms of retinal ganglion cells retrogradely labeled with HRP for the cytochrome $\mathrm{c}$ and NGF retinas, 5 $(A)$ and $7(B)$ weeks after optic nerve section, compared with the soma size distribution of RGCs from a normal retina. left with NGF. Seven more animals had only the right optic nerve transected. Three animals were treated with NGF, and 4 with cytochrome $\mathrm{c}$.

In the initial analysis, the diameter distribution of myelinated fibers was measured. The axon diameter distribution and an electron micrograph of a normal optic nerve are given in Figure $5 A$, while the results obtained from a rat 5 weeks after section of both the optic nerves are presented in Figure $5, B, C$. Compared with normal optic nerve, the axon diameter distribution of the cytochrome $c$ optic nerve shows a marked decrease in the number of large axons and a relative increase in the number of small axons. On the left is shown an electron micrograph taken from the paracentral belt of the nerye (see Materials and Methods). Note that only several small myelinated fibers are present. The axon diameter distribution of the NGF optic nerve is shown in Figure $5 C$. Although there is also a decrease in the number of large axons with respect to normal, this decrease is less marked with respect to the contralateral optic nerve. On the left is shown an electron micrograph of the paracentral belt of the nerve. It can be noted that the density of myelinated fibers in this region of the NGF optic nerve is higher than in the corresponding region of the cytochrome $c$ nerve, and several large fibers are still present. Results obtained from 5 cytochrome $c$ and 4 NGF optic nerves are reported in the summary histograms of Figure 6. Thus, it appears that NGF is particularly effective in preserving large-caliber axons. This effect is in keeping with the phenomenon already observed at the level of the RGCs, where the effect of NGF was noted to be more apparent on large cells.

Furthermore, the number of myelinated axons was also determined. This analysis was performed in thin sections taken 2 $\mathrm{mm}$ from the globe. Although a certain degree of variability was noted, the number of myelinated fibers was always greater in NGF optic nerves than in cytochrome $c$ nerves. Five weeks after optic nerve section, the mean number of myelinated fibers in the NGF group was $24,721 \pm 431(n=2)$, whereas in the cytochrome $\mathrm{c}$ group this value was $12,432 \pm 1023(n=3)$. After 7 weeks, these values were $19,488 \pm 2392(n=5)$ and $8660 \pm$ $1948(n=5)$, respectively, in the NGF and cytochrome c groups $(p<0.01)$.

Table 1. Effect of axotomy on the soma diameter $(\mu \mathrm{m})$ of HRP-labeled RGCs

\begin{tabular}{|c|c|c|c|c|}
\hline & Cytoc & & NGF & \\
\hline & Code & Median & Code & Median \\
\hline Control animals & R9 $9^{a}$ & 11.5 & $\mathbf{R} 10^{b}$ & 11.1 \\
\hline 5 weeks after axotomy & $\mathbf{R} 1$ & 7.2 & $\mathrm{R} 2$ & 11.8 \\
\hline & R3 & 8.5 & R4 & 12.8 \\
\hline & R5 & 8.8 & R6 & 13.3 \\
\hline & R7 & 8.3 & $\mathrm{R} 8$ & 9.5 \\
\hline Mean \pm SEM & & $8.2 \pm 0.34$ & & $11.8 \pm 0.84$ \\
\hline 7 weeks after axotomy & R11 & 8.7 & $\mathrm{R} 12$ & 11.9 \\
\hline & R13 & 7.7 & $\mathrm{R} 14$ & 8.9 \\
\hline & $\mathrm{R} 15$ & 10.2 & $\mathrm{R} 16$ & 9.9 \\
\hline & $\mathrm{R} 17$ & 7.7 & $\mathrm{R} 18$ & 10.8 \\
\hline & R19 & 8.0 & & \\
\hline Mean \pm SEM & & $8.5 \pm 0.47$ & & $10.4 \pm 0.64$ \\
\hline
\end{tabular}

${ }_{a . b}$ In these animals optic nerve section was not performed, but R10 received NGF repetitive intraocular injections for 5 weeks. 


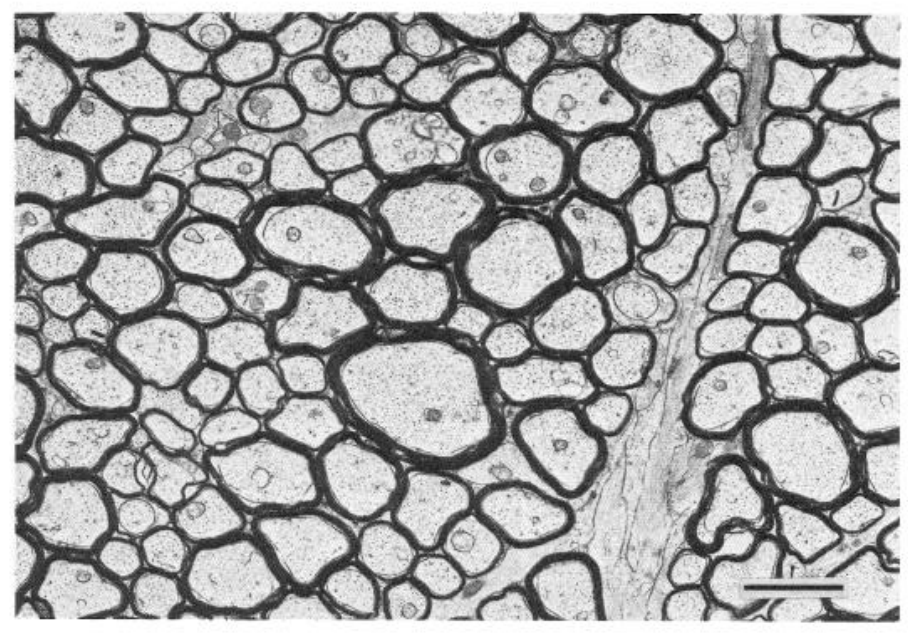

A
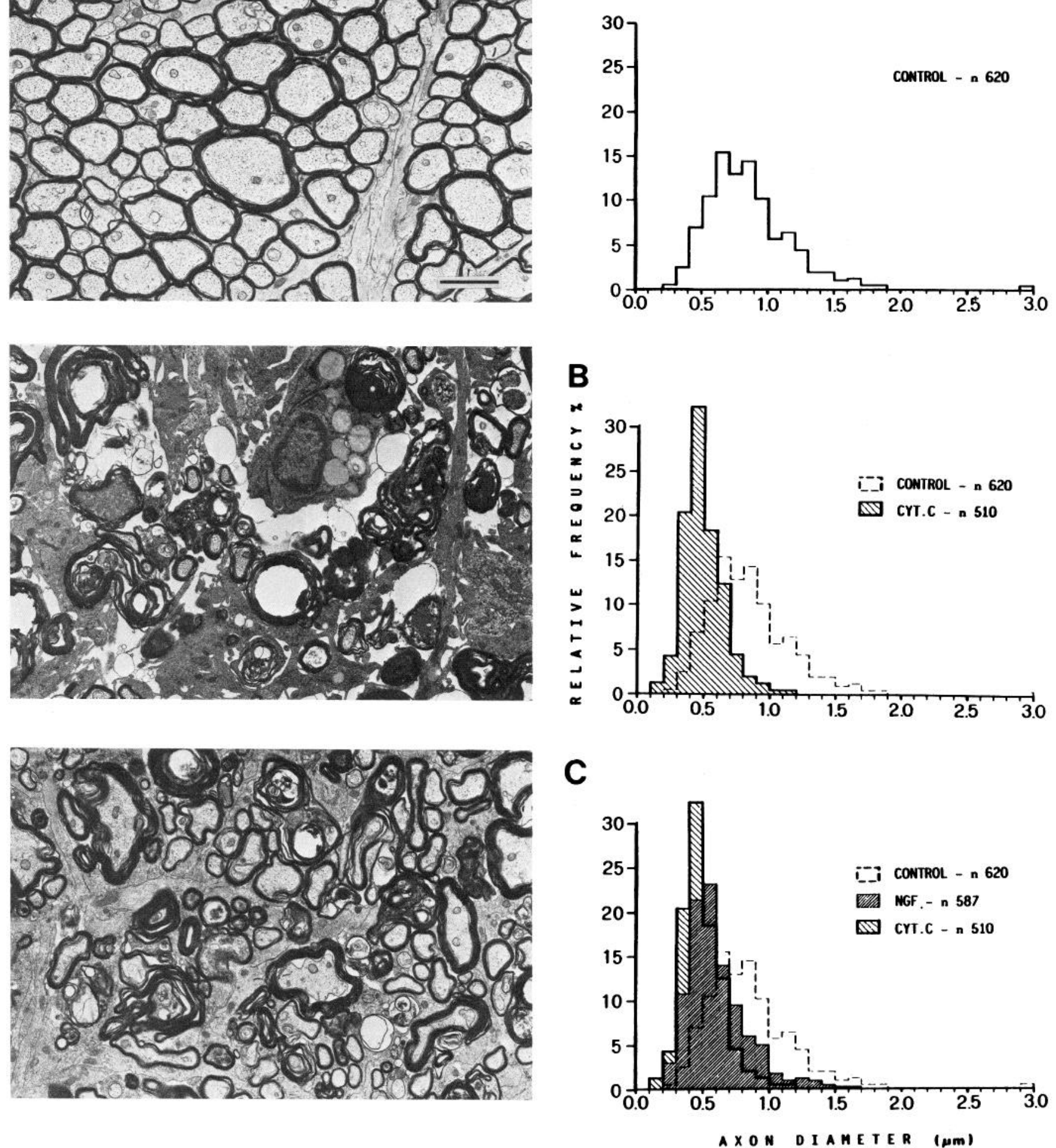

Figure 5. Electron micrographs and axon diameter distributions of a normal optic nerve $(A)$ and of the right $(B)$ and left $(C)$ optic nerves of a rat 5 weeks after bilateral optic nerves transection. The right eye $(B)$ was treated with cytochrome $c$ and the left $(C)$ with NGF. Note that in $B$ large myelinated fibers are absent, whereas in $C$ several large fibers can be observed. The 2 micrographs represent corresponding regions of the cytochrome $\mathrm{c}$ and NGF optic nerves. Scale bar, $2 \mu \mathrm{m}$. All micrographs are at the same magnification. 

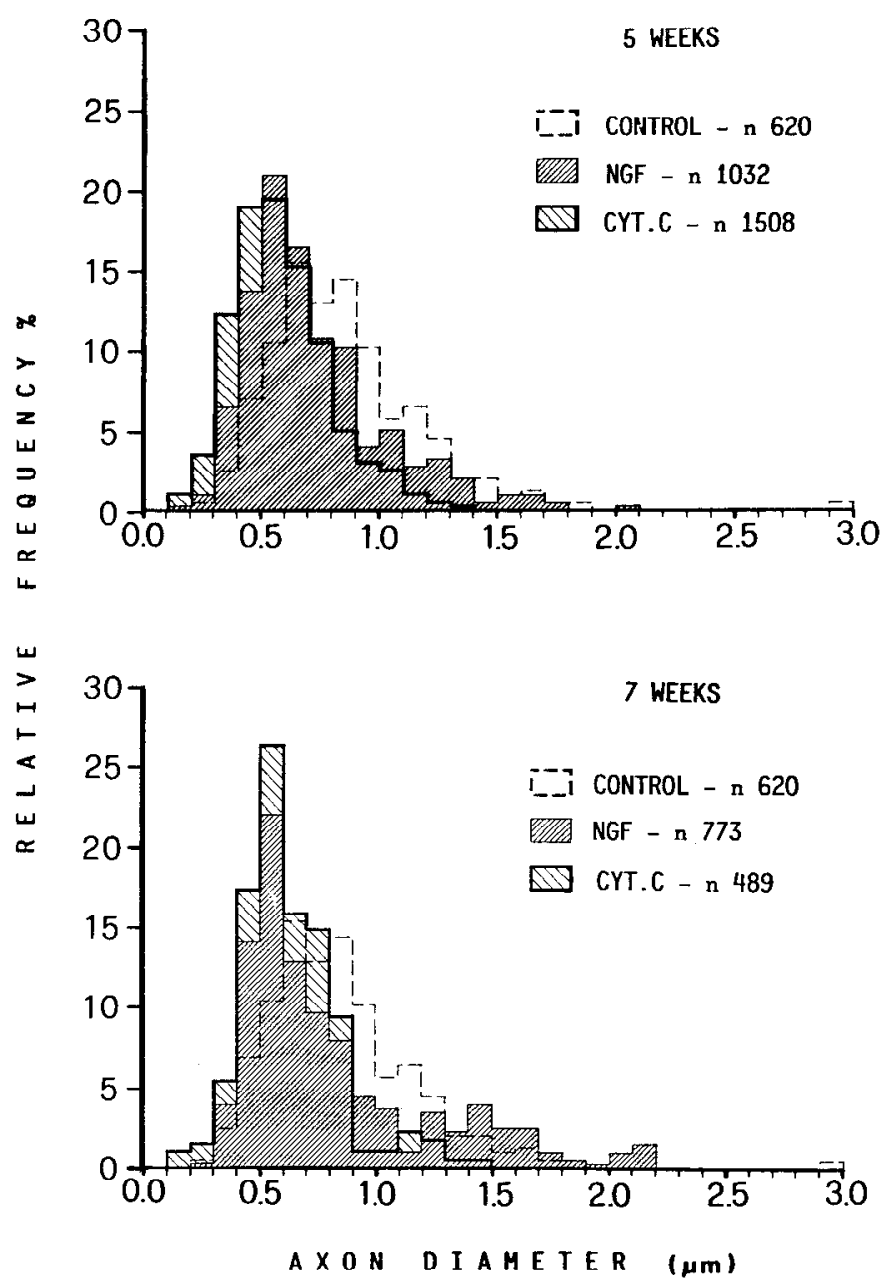

Figure 6. Summary histograms of axon diameter distributions of the cytochrome $c$ and NGF optic nerves 5 and 7 weeks postaxotomy.

\section{Retrograde transport of ${ }^{225} I-N G F$ from the $S C$}

Since the action of NGF is usually bound to the presence of NGF receptors, we examined whether ${ }^{125}$ I-NGF is retrogradely transported by RGCs following its administration into the SC, which is the main target of retinal ganglion cell axons. At 4, 8 , and $16 \mathrm{hr}$ after right $\mathrm{SC}$ injection, there was no difference between the contralateral retina, whose main target had been injected with ${ }^{125}$ I-NGF and the ipsilateral retina. Very few counts were obtained in either retina, and radioactivity was found to be at background level.

\section{Discussion}

Interruption of optic nerve fibers in mammals results in the progressive retrograde degeneration of axons and death of RGCs. One month after axotomy myelinated axons are less than $10 \%$ with respect to controls (Richardson et al., 1982), and the number of RGCs is also markedly reduced (Miller and Oberdorfer, 1981; Grafstein and Ingoglia, 1982; Barron et al., 1986).

The results of the present work indicate that prolonged repetitive intraocular injections of NGF promote the survival of a remarkable number of RGCs, at least for periods as long as 7 weeks from transection of the optic nerve.

In order to assess in reliable quantitative terms the effect of
NGF, we counted the optic nerve fibers at the electron microscopic level. This analysis shows that the number of myelinated fibers is significantly greater in NGF-treated animals than in controls. We like to emphasize that the axon diameter distribution is in agreement with the size distribution of surviving RGCs. In both cases, the size distribution is similar to that of normal animals. Fibers and cells of large size, i.e., fibers with diameters greater than $0.8 \mu \mathrm{m}$ and cells with soma diameters greater than $15 \mu \mathrm{m}$, which are almost absent in control animals, are, in fact, present in animals treated with NGF.

However, not all RGCs are rescued by NGF. This partial effect may be due to insufficient availability to ganglion cells of NGF or to differential sensitivity to NGF of RGC subpopulations. Recently, it has been reported that NGF, after an intraretinal axonal lesion in chicken, is active in promoting survival of that class of RGCs that is substance P-positive (Ehrlich et al., 1989).

The effect of NGF on large RGCs might result from a nonspecific effect on smaller size RGCs, which are rendered hypertrophic by NGF. This hypothesis seems unlikely for the following reasons. First, the size distributions of RGCs in a normal control retina and that of RGCs in NGF retinas are quite similar. Second, the dendritic tree and soma of RGCs in NGF retinas appear rather healthy and indistinguishable from normal. Third, other than being active on large RGCs, NGF is likewise effective in preserving large-caliber optic nerve fibers. A nonspecific effect of hypertrophy by NGF on fibers is unlikely, since at the ultrastructural level the axoplasm and myelin sheath of large fibers, which were included in the analysis of the diameter distribution, appear to be normal.

\section{Possible targets of $N G F$ in the retina}

Several recent observations indicate that NGF, in addition to its well-known role for peripheral sympathetic and sensory neurons (Levi-Montalcini and Angeletti, 1968; Greene and Shooter, 1980; Varon and Adler, 1980; Johnson et al., 1986) may also display a trophic function for basal forebrain cholinergic neurons in the CNS. Administration of NGF is reported to prevent the degeneration of these neurons following interruption of their projection to the hippocampus and neocortex (Hefti et al., 1984; Hefti, 1986; Williams et al., 1986; Kromer, 1987). These latter neurons have receptors for NGF and exhibit a specific uptake and retrograde transport of ${ }^{125} \mathrm{I}-\mathrm{NGF}$ injected into their target regions (Schwab et al., 1979; Seiler and Schwab, 1984; Richardson et al., 1986). NGF intraocular administration has also been shown to enhance the regeneration of the goldfish optic nerve (Turner et al., 1980; Yip and Grafstein, 1982). Our experiments showed that NGF, as already described for the goldfish visual system (Yip and Johnson, 1983), is not retrogradely transported by intact RGCs in adult rat. NGF receptors have not been detected in the ganglion cell layer of adult rat normal retina. However, NGF-like immunoreactivity is present during early development of the mouse visual system, at E16 at the level of the inner retinal layer, optic nerve, and tectum (Finn et al., 1987), and NGF receptor has also been identified immunohistochemically up to postnatal day 10 in the ganglion cell layer of the rat retina (Loy and Koh, 1986; Yan and Johnson, 1988). The absence of NGF receptor in normal adult animals does not exclude, on theoretical grounds, the possibility that it may he reexpressed in particular experimental and/or pathological situations. Indeed, recent experiments in our laboratory (L. Cavicchioli, P. Condeo, L. Maffei, and G. Carmignoto, un- 
published observations) have shown that the mRNA for NGF receptor is highly expressed at the level of the rat retina not only during the prenatal life, but also in adult life following optic nerve section and NGF administration. At present, we do not know in which population of retinal cells the NGF receptor gene is expressed. RGCs as well as Müller cells, which have been shown in primate retinas to possess NGF receptors (Schatteman et al., 1988), are possible candidates.

\section{Concluding remarks}

A number of studies have recently appeared describing attempts to rescue damaged CNS neurons from degeneration and to promote their regeneration. The main strategies used have been based either on a pharmacological approach (direct administration of specific molecules into the CNS) or on transplantation of fetal neurons and peripheral nerve segments (Benfey and Aguayo, 1982; So and Aguayo, 1985; Berry et al., 1986; Sievers et al., 1987; Vidal-Sanz et al., 1987; Villegas-Perez et al., 1988) into CNS districts. This latter line of experiments has been mainly followed by Aguayo and his group, and relies on the observation that transplantation of a peripheral nerve increases the number of cells surviving axotomy and that CNS neurons do, at least in part, regenerate their injured axons into a grafted peripheral nerve. A major component of this type of experiment is pharmacological in nature since, as the authors point out, the process of regeneration obtained in several regions of the CNS, included the optic nerve (for review, see Aguayo, 1985), is likely based on the presence of Schwann cells. These cells are believed to exert a tropic influence on the growth of injured axons (Ide et al., 1983), but more interestingly, Schwann cells have been demonstrated to produce, when activated by the loss of axonal contact, considerable amounts of NGF (Korshing et al., 1986; Abrahmson et al., 1987). It cannot therefore be excluded that the results obtained by Aguayo and coworkers (Villegas-Perez et al., 1988) and ours have, at least in part, some common features. In both cases, NGF could be the active factor in promoting the survival of axotomized RGCs. In the present experiments, NGF was supplied exogenously, while in the experiments by Aguayo and coworkers, NGF could be produced by the Schwann cells of the grafted sciatic nerve. Indeed, at a quantitative level, the number of surviving RGCs seems comparable in the 2 experiments. We belicve that the combination of these 2 strategies may offer new important clues for successful regeneration of CNS neurons.

\section{References}

Abrahmson, I. K., D. Bridges, and R. A. Rush (1987) Transport of endogenous nerve growth factor in the proximal stump of sectioned nerves. J. Neurocytol. 16: 417-422.

Aguayo, A. J. (1985) Axonal regeneration from injured neurons in the adult mammalian central nervous system. In Synaptic Plasticity. C. W. Cotman, ed., pp. 457-484, Guilford, New York.

Barron, K. D., M. P. Dentinger, G. Krohel, S. K. Easton, and R. Mankes (1986) Qualitative and quantitative ultrastructural observations on retinal ganglion layer of rat after intraorbital optic nerve crush. J. Neurocytol. 15: 345-362.

Benfey, M., and A. J. Aguayo (1982) Extensive elongation of axons from rat brain into peripheral nerve grafts. Nature 296: 150-152.

Berry, M., L. Rees, and J. Sievers (1986) Regeneration of axons in the mammalian visual system. Exp. Brain Res. (Suppl.) 13: 18-33.

Bocchini, V., and P. U. Angeletti (1969) The nerve growth factor: Implication as a 30,000 molecular-weight protein. Proc. Natl. Acad. Sci. USA 64: 787-794.

Ehrlich, D., K. Keyser, M. Manthorpe, S. Varon, and H. Karten (1988) Differential effects of axotomy on substance P-containing and nico- tinic acetylcholine receptor-containing retinal ganglion cells: Time course of degeneration and effects of nerve growth factor. Neuroscience (in press).

Finn, P. J., F. A. Ferguson, P. A. Wilson, J. Vahaviolos, and R. A. Rush (1987) Immunohistochemical evidence for the distribution of nerve growth factor in the embryonic mouse. J. Neurocytol 16: 639-647.

Grafstein, B. (1986) The retina as a regenerating organ. In The Retina. A Model for Cell Biology Studies, R. Adler and D. Farber, eds., pp. 275-335, Academic, New York.

Grafstein, B., and N. A. Ingoglia (1982) Intracranial transection of the optic nerve in adult mice: Preliminary observations. Exp. Neurol. 76 : 318-330.

Greene, L. A., and E. M. Shooter (1980) The nerve growth factor: Biochemistry, synthesis, and mechanism of action. Annu. Rev. Neurosci. 3: 353-402.

Gundersen, H. J. L. (1977) Notes on the estimation of the numerical density of arbitrary profiles: The edge effect. J. Microsc. 111: 219223.

Hanker, J. S., P. E. Yates, C. B. Metz, and A. Rustioni (1977) A new specific and non-carginogenic reagent for the demonstration of horseradish peroxidase. Histochem. J. 9: 787-792.

Hefti, F. (1986) Nerve growth factor promotes survival of septal cholinergic neurons after fimbrial transections. J. Neurosci. 6:2155-2162.

Hefti, F., A. Dravid, and J. Hartikka (1984) Chronic intraventricular injections of nerve growth factor elevate hippocampal choline acetyltransferase activity in adult rats with partial septo-hippocampal lesions. Brain Res. 293: 305-311.

Hollander, H., S. Bisti, L. Maffei, and R. Hebel (1984) Electroretinographic responses and retrograde changes of retinal morphology after intracranial optic nerve section. A quantitative analysis in the cat. Exp. Brain Res. 55: 483-493.

Ide, C., K. Tohyma, R. Yokota, T. Nitatori, and S. Onodera (1983) Schwann cell basal lamina and nerve regeneration. Brain Res. 288: 61-75.

Johnson, E. M., K. M. Rich, and H. K. Yip (1986) The role of NGF in sensory neurons "in vivo." Trends. Neurosci. 1: 33-37.

Korshing, S. I., R. Heumann, A. Davis, and H. Thoenen (1986) Levels of nerve growth factor and its mRNA during development and regeneration of the peripheral nervous system. Soc. Neurosci. Abstr. 12: 1986 .

Kromer, L. F. (1987) Nerve growth factor treatment after brain injury prevents neuronal death. Science 235: 214-216.

Landmesser, L., and G. Pilar (1974) Synaptic transmission and cell death during normal ganglionic development. J. Physiol. (Lond.) 241: $737-749$.

Levi-Montalcini, R., and P. U. Angeletti (1968) Nerve growth factor. Physiol. Rev. 48: 534-569.

Loy, R., and S. Koh (1986) Developmental expression of nerve growth factor receptors in sensory systems of the rat CNS. Soc. Neurosci. Abstr. 12: 393.

Maffei, L., and A. Fiorentini (1981) Electroretinographic responses to alterating gratings before and after section of the optic nerve. Science 211: 953-955.

McConnell, P., and M. Berry (1982) Regeneration of ganglion cell axons in the adult mouse retina. Brain Res. 241: 362-365.

Miller, N. M., and H. Oberdorfer (1981) Neuronal and neuroglial responses following retinal lesions in the neonatal rats. J. Comp. Neurol. 202: 493-504.

Misantone, L. J., M. Gershenbaum, and M. Murray (1984) Viability of retinal ganglion cells after optic nerve crush in adult rats. J. Neurocytol. 13: 449-465.

Perry, V. H. (1979) The ganglion cell layer of the retina of the rat: A Golgi study. Proc. R. Soc. London [Biol.] 204: 364-375.

Perry, V. H. (1981) Evidence for an amacrine cell system in the ganglion cell layer of the rat retina. Neuroscience 6: 931-944.

Perry, V. H., and A. Cowey (1979) The effects of unilateral cortical and tectal lesions on retinal ganglion cells in rat. Exp. Brain Res. 35. $85-95$.

Perry, V. H., and R. Linden (1982) Evidence for dendritic competition in the developing retina. Nature 297: 683-685.

Richardson, P. M., V. M. K. Issa, and S. Schemie (1982) Regeneration and retrograde degeneration of axons in the rat optic nerve. J. Neurocytol. 11: 949-966.

Richardson, P. M., V. M. K. Issa, and R. J. Riopelle (1986) Distribution of neuronal receptors for nerve growth factor in the rat. $\mathrm{J}$ Neurosci. 6: 2312-2321. 
Schatteman, G. C., L. Gibbs, A. A. Lanahan, P. Claude, and M. Bothwell (1988) Expression of NGF receptors in the developing and adult primate central nervous system. J. Neurosci. 8: 860-873.

Schwab, M., U. Otten, Y. Agid, and H. Thoenen (1979) Nerve growth factor (NGF) in the rat CNS: Absence of specific retrograde axonal transport and tyrosine hydroxylase induction in locus coeruleus and substantia nigra. Brain Res. 168: 473-483.

Seiler, M., and M. E. Schwab (1984) Specific retrograde transport of nerve growth factor (NGF) from neocortex to nucleus basalis in the rats. Brain Res. 300: 33-39.

Sievers, J., B. Hausemann, K. Unsicker, and M. Berry (1987) Foetal brain graft and FGF promote survival and axons regeneration of adult rat retinal ganglion cells. Neuroscience (Suppl). 22: 264.

Skaper, S. D., and S. Varon (1982) Three independent biological assays for nerve growth factor: No measurable activity in human sera. Exp. Neurol. 76: 655-665.

So, K. F., and A. J. Aguayo (1985) Lengthy regrowth of cut axons from ganglion cell axons after peripheral ncrve transplantation into the retina of adult rats. Brain Res. 328: 349-354.

Thoenen, H., C. Bandtlow, and R. Heumann (1987) The physiological function of nerve growth factor in the central nervous system: Comparison with the periphery. Rev. Physiol. Pharmacol. 109: 145-171.

Turner, J. E., R. K. Delaney, and J. E. Johnson (1980) Retinal ganglion cell response to nerve growth factor in the regenerating, and intact visual system of the goldfish ("carassius auratus"). Brain Res. 197: 319-330.
Varon, S., and R. Adler (1980) Nerve growth factor and control of nerve growth. Topics Dev. Biol. 16: 207-252.

Varon, S., L. R. Williams, and F. H. Gage (1987) Exogenous administration of neuronotrophic factors in vivo protects central nervous system neurons against axotomy induced degeneration. Brain Res. 71: 191-201

Vidal-Sanz, M., G. M. Bray, M. P. Villegas-Perez, S. Thanos, and A. J. Aguayo (1987) Axonal regeneration and synapse formation in the superior colliculus by retinal ganglion cells in the adult rat. J. Neurosci. 7: 2894-2909.

Villegas-Perez, M. P., M. Vidal-Sanz, and A. J. Aguayo (1988) Influence of peripheral nerve grafts on the survival and regrowth of axotomized retinal ganglion cells in adult rats. J. Neurosci. 8: 265-280.

Yan, Q., and E. M. Johnson, Jr. (1988) An immunohistochemical study of the nerve growth factor receptor in developing rats. J. Neurosci. 8: 3481-3498.

Yip, H. K., and B. Grafstein (1982) Effect of nerve growth factor on regeneration of goldfish optic axons. Brain Res. 238: 329-339.

Yip, H. K., and E. M. Johnson (1983) Retrograde transport of nerve growth factor in lesioned goldfish retinal ganglion cells. J. Neurosci. 3: 2172-2182

Williams, L. R., S. Varon, G. M. Peterson, K. Wictorin, W. Fisher, A. Björklund, and F. H. Gage (1986) Continuous infusion of nerve growth factor prevents basal forebrain neuronal death after fimbria fornix transection. Proc. Natl. Acad. Sci. USA 83: 9231-9235. 